ORIGINAL ARTICLE

\title{
Studying the induction effect of different mouse neck scaffolds on the behavior of Mouse Bone marrow-derived mesenchymal stem cell
}

\author{
MOHAMADKAZEM GANJAVI ${ }^{1,2}$, MOHAMADREZA BAGHABAN ESLAMINEJAD ${ }^{2}$, NASSER MAHDAVI-SHAHRI ${ }^{*}$, YASER \\ TAHMTANI ${ }^{4,2}$ \\ ${ }^{1}$ Faculty of Sciences and Advanced Technologies in Biology, University of Science and Culture, Tehran, Iran \\ ${ }^{2}$ Department of Stem Cells and Developmental Biology, Cell Science Research Center, Royan Institute for Stem Cell Biology and \\ Technology, ACECR, Tehran, Iran \\ ${ }^{3}$ Department of Biology, Kavian institute of higher Education, Mashhad, Iran \\ ${ }^{4}$ Reproductive Epidemiology Research Center, Royan Institute for Reproductive Biomedicine, ACECR, Tehran, Iran \\ ${ }^{*}$ Corresponding author: mahdavin@um.ac.ir
}

\begin{abstract}
Objective: Studying the behavior of mesenchymal stem cells is important for understanding some physiological and pathological processes as well as long-term preservation of these cells in vitro. The neck area of mouse contains a wide variety of different organs and tissues and extracellular matrices. In the present study, the interaction of mouse bone marrow derived mesenchymal stem cells (BM-MSCs) with mouse neck scaffolds was performed in order to have a better understanding of the behavior of mesenchymal stem cells.

Materials and methods: The neck areas of 9 two-week-old Syrian mice were cut into pieces with $4 \mathrm{~mm}$ thickness. Decellularization process was carried through snap freeze-thaw cycles followed by sodium dodecyl sulfate (SDS) treatments. After confirmation of acellularization through histological studies and DNA extraction process, scaffolds were co-cultured with mouse (BM-MSCs) up to 21 days, in vitro.

Results: As indicated by histological studies and scanning of electron microscopy, stem cells migrate into the cartilage scaffold on third, seventh and fourteenth days of culture. Stem cells were divided on these days. On the fourteenth day of culture, migration to epidermal and blood vascular scaffolds was also observed. On the twentyfirst day of culture, cells were observed only in the cartilage scaffold, while showing morphological differentiation. Conclusion: As indicated by the results of the present study, mouse neck scaffold, due to its diverse extracellular matrices, is a suitable structure for studying some cellular behaviors such as migration, cell division and cell differentiation. However, more molecular studies are needed to determine the extent of this differentiation.

Keywords: Natural scaffold, Cell behaviors, Cell-matrix interaction, Experimental model scaffolding, mouse neck area
\end{abstract}

\section{INTRODUCTION}

Extracellular matrix (ECM) is Nature's perfect biological scaffold material [1]. It is a complicated web of proteins, glycoproteins and proteoglycans forming a complex meshwork inside the tissue that interacts with the resident cells to modulate cell behaviors [2, 3]. In order to study cellmatrix interaction in vitro, two essential pillars are involved; scaffold and appropriate cell source.

Scaffolds play an important role in providing a threedimensional structure for cell growth in vitro, as one of the most important pillars of tissue engineering [4]. They usually have a porous structure similar to the extracellular matrix and are divided into natural and synthetic groups [5]. So far, various synthesized scaffolds have been developed to examine the behavior of cells in three-dimensional conditions but each of these scaffolds has defects such as the lack of control over the adhesion of cells and so on. The extracellular matrix of living organisms can also be used for studying the behavior of cells. To do this, decellularization techniques can be used to remove the effect of tissue cells from the extracellular matrix, so that ultimately, only the extracellular matrix can remain from the tissue and can be used as a scaffold. The purpose of the decellularization process is to remove the cellular and nuclear material while maintaining integrity and minimizing any damage to the composition and bioavailability of the extracellular matrix [6]. Nowadays, scaffolds derived from decellularization of tissues such as heart and heart valves, blood vessels, submucosa of small intestine, lung, pancreas, trachea, skin, nerve, cornea, liver, kidney, bladder, muscle, tendon, adipose tissue, amniotic membrane and etc are prepared, some of them have even been commercialized for clinical applications [7].

Most of the cellular resources usually used in cell- matrix interactions including fibroblastic, stem and cancerous cells [8]. Mesenchymal stem cells have the capacity to proliferate well in vitro and differentiate to various mesenchymal tissues such as bone, cartilage, fat, muscle and etc (9). However, one of the clinical limitations of these cells is that they age rapidly and lose their stemness potential rapidly after extraction and culture in vitro [10,11]. The neck area of the mouse is made of a variety of organs and tissues such as skin, white fat, brown fat, cartilage, bone, skeletal muscle, blood vessels, larynx, trachea, esophagus, salivary glands, lymph nodes, thyroid and parathyroid glands, thymus, spinal cord and peripheral nervous system which include a wide variety of extracellular matrices (Figure 1). 
A

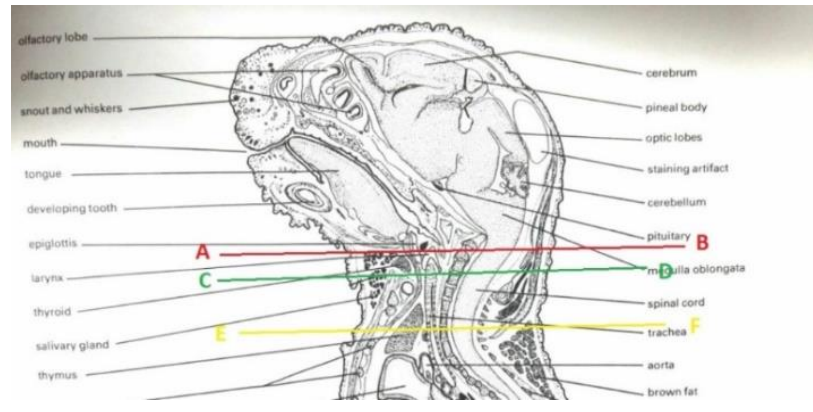

B

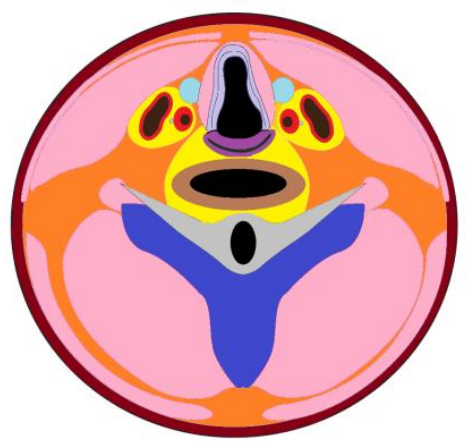

Incision line A-B

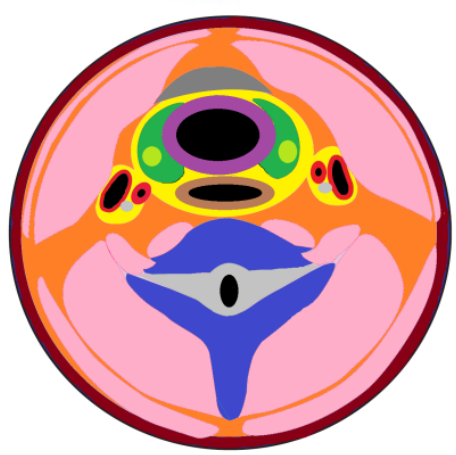

Incision line C-D

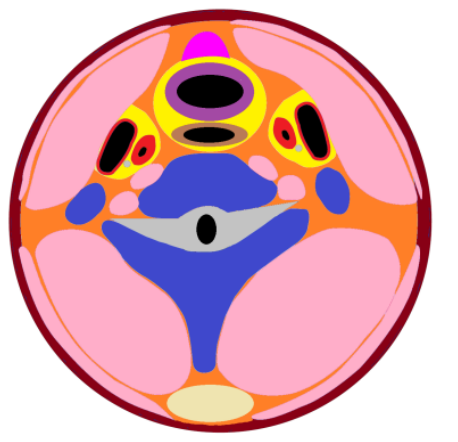

C

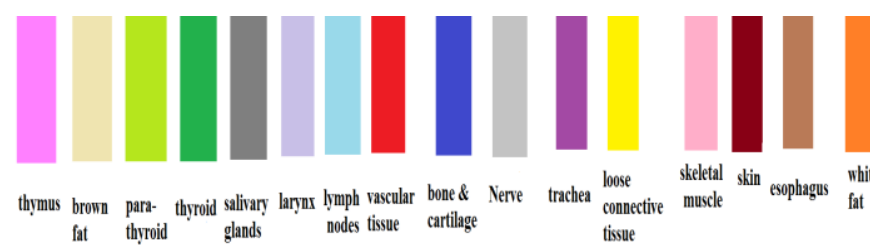

Figure 1: Schematic display of type and position of mouse neck tissues.

Incision line E-F
A: Longitudinal incision display of mouse neck tissues. Three incision lines are shown. B: Transverse incision display of mouse neck tissues based on three incision lines in part A. C: Mouse neck tissues that are shown in different colors based on part $B$

The aim of the recent study is to prepare a mouse neck area scaffold model for studying cell-matrix interactions to better understand the behavior of mesenchymal stem cells.

\section{MATERIAL AND METHODS}

Studying mouse neck tissues: In order to prepare a three-dimensional natural scaffold from the neck area of the mouse, nine two-week-old Syrian mice were first anesthetized with chloroform. The mice were then frozen at $-4 \hat{c}$ to separate their neck area more easily. The neck areas of the mice were then cut into pieces with $4 \mathrm{~mm}$ thickness. One of these neck fragments was immediately prepared for histological evaluation.

Preparation of mouse neck scaffold: For physical decellularization, eight pieces of mouse neck areas were maintained at -4 c for a week. After thawing and washing specimens with normal saline, chemical decellularization was applied. To do this, specimens were treated with $2.5 \%$ and 5\% SDS (Merck, Darmstadt, Germany) in a shaker at $200 \mathrm{rpm}$ and $37 \hat{\mathrm{c}}$ for about 3 hours to achieve the best elimination of cells, while preserving the extracellular matrix components. Then, the specimens were rinsed in phospahate-buffered saline (PBS) for $30 \mathrm{~min}$. in the next step, in order to remove SDS and minimize potential contaminations, the decellularized scaffolds were placed in a sterile Buchner funnel and washed with $75 \%$ ethanol, sterile distilled water and PBS, respectively. Different preparations were used to evaluate decellularization including histological Evaluation, DNA extraction analysis, semi-thin preparation and Scanning electron microscoy.

DNA extraction analysis: DENAzist animal tissue DNA isolation kit was used for extraction of genomic DNA from normal and decellularized mouse neck area. According to the protocol $10-15 \mathrm{mg}$ of tissue was weight and DNA extraction process was done based on three steps: DNA release \& binding to column, washing and elution.

Bone marrow-derived mesenchymal stem cells isolation and expansion: Mesenchymal stem cells were derived from four-week-old Syrian mouse bone marrow and transferred into a cell culture flask filled with $5 \mathrm{ml}$ Dulbeccos modified Eagles medium (DMEM, Gibco, Paisley, Scotland) supplemented with $15 \%$ fetal bovin serum, (FBS, Gibco, Scotland) and $100 \mu \mathrm{l}$ penicillin/streptomycin (Biosera, Sussex, UK). Cells were then incubated at $37 \hat{\mathrm{c}}$ and $0.5 \% \mathrm{Co} 2$ in air. After the removal of blood and stromal cells, BM-MSCs were subcultured and purified by trypsinization $(0.25 \%$ trypsin/EDTA (Ethylenediamineteraacetic acid solution, Biosera, Sussex, UK) for four times [12, 13].

Seeding and culture method: BM-MSCs at passages 4 were trypsinized, counted and the scaffolds were seeded with $5 \times 10^{5}$ cells/scaffold in $2 \mathrm{ml}$ complete medium, and specimens were placed in 24-well plates. Seeding was performed in a drop wise fashion on the scaffold. Seeded scaffolds were incubated in a humidified atmosphere at 
$37^{\circ} \mathrm{C}$ with $5 \% \mathrm{CO} 2$ in air. The medium was changed every 2 to 3 days. Some unseeded scaffolds were cultured as controls. Histological evaluation, semi thin preparation and scanning electron microscopy were performed after 3, 7, 14 and 21 days of culture.

Histological evaluation: Paraformal - Fixed and paraffin embedded (Sigma-Aldrich) tissue sections were cut into 5 thick parts, and were stained with Hematoxylin and Eosin, toluidine blue, masson trichrome and DAPI.

Semi-thin preparation: Normal and decellularized mouse neck fragments were fixed in $2.5 \%$ glutaraldehyde in $0.1 \mathrm{M}$ sodium cacodylate buffer following with osmium tetroxide fixative. After washing with sodium cacodylate buffer, dehydration was performed with increasing degrees of alcohol. Specimens were then impregnated with propylene oxide and resin combinations and the final impregnation was performed in pure resin for 24 hours. Finally resin molding and cutting with ultramicrotum with a thickness of $1000 \mathrm{~nm}$ was performed and specimens were stained with toluidine blue [14].

Scanning electron microscopy (SEM): In order to prepare samples for electron microscopy, the specimens were fixed with $2.5 \%$ glutaraldehyde (TAAB Laboratories Equipment Ltd. Reading, UK) for $24 \mathrm{hr}$ followed by three 15 min washes in $0.1 \mathrm{M}$ sodium cacodylate buffer $(\mathrm{pH} 7.4$, TAAB Laboratories Equipment Ltd. Reading, UK). Then, the specimens were treated with $1 \%$ Osmium tetroxide (TAAB Laboratories, UK) for $1 \mathrm{hr}$ and washed in $0.1 \mathrm{M}$ sodium cacodylate buffer. At the next step, the sections were subjected to sequential dehydration with $30 \%, 50 \%$, $70 \%, 90 \%$, and absolute ethanol solutions, followed by three washes with absolute ethanol for $15 \mathrm{~min}$. Then the specimens were fixed on metal stubs and coated with goldpalladium by sputtering (Sputter coater, SC7620, Sussex, UK) and examined under a scanning electron microscope (SEM; LEO 1450VP, Oberkochen, Germany).

Statistical analysis: Image j software was used to evaluate the percentage of cartilage scaffold occupied by mesenchymal stem cells and also to measure the color intensity of cartilage scaffold. For statistical analysis, GraphPad Prism (8th version) software and Kruskal-Wallis test and Dunn's multiple comparisons analysis were used

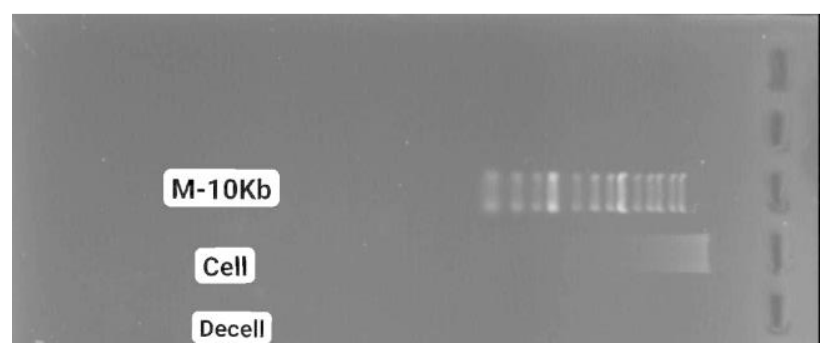

to determine the statistically significant difference between different groups. Significant differences between groups were displayed as $p<0.05^{*}$.

\section{RESULTS}

The histological investigations showed the presence of various tissues and organs, including the spine (contains bone-cartilage), bone marrow, ribs, skin, adipose tissue, skeletal muscle tissue, vascular tissue, esophagus, trachea, thymus, spinal cord and peripheral nervous system (some of them are shown in figure 1) within mouse neck area.

DNA extraction analysis (figure 2) as well as histological investigations (figure 3) showed proper decellularization and relatively good preservation of extracellular matrix compounds. However, in the cartilage tissue (probably due to the presence of lacunae) as well as in the esophagus (probably due to the twisted structure), fragments of genetic material were trapped and not completely removed (figure 3). Despite complete decellularization, Semi-thin and scanning electron microscopy investigations showed the presence of many fat vacuoles within dermal scaffold (figure 4).

Confocal microscopy image of mouse BM-MSCs in the fourth passage that were used for seeding is shown (figure 5). Co-culture investigations showed the migration of mouse BM-MSCs on the cartilage scaffold on days third, seventh and fourteenth of culture (figure 6). In These days, divided cells were also observed within the cartilage scaffold (figure $6 \mathrm{~A}, 6 \mathrm{~B} \& 6 \mathrm{C}$ ). On the $14^{\text {th }}$ day of culture, the highest percentage of the cartilage scaffold area occupied by mouse BM-MSCs was also observed (Diagram 1). Migrations to the epidermal and blood vascular scaffolds were also observed on this day (figure $8 \& 9$ ). On the $21^{\text {st }}$ day of culture, the cells were observed only in cartilage scaffold, while showing morphological differentiation. No cell division was also observed on this day (figure 6D). On the other hand the color intensity of mouse neck cartilage scaffold was decreased significantly on this day (figure 6D \& Diagram 2).

Figure 2: DNA extraction analysis display of normal and decellularized mouse neck area 

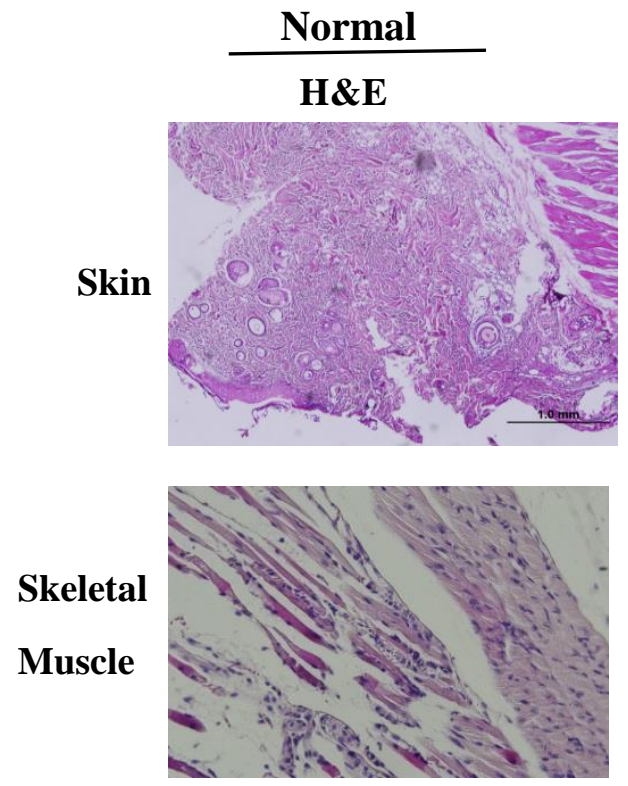

Adipose

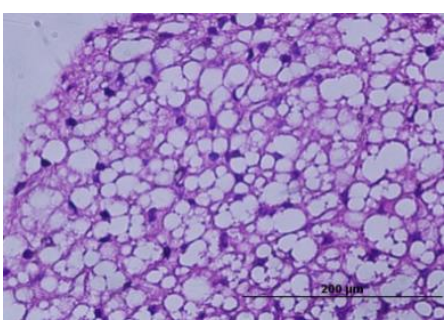

\section{Cartilage}

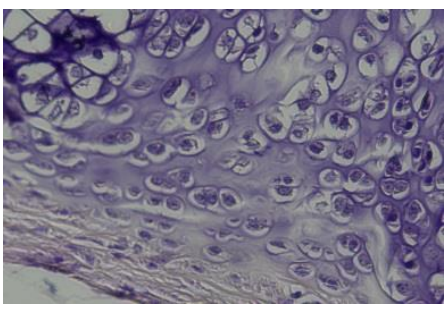

Esophagus
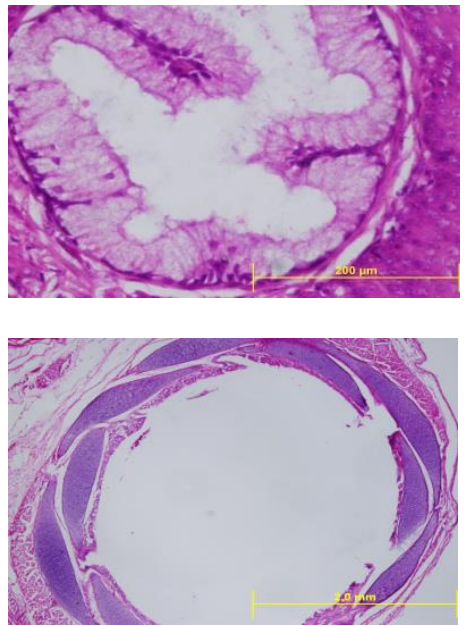

Decell

H\&E/ Toluidine blue
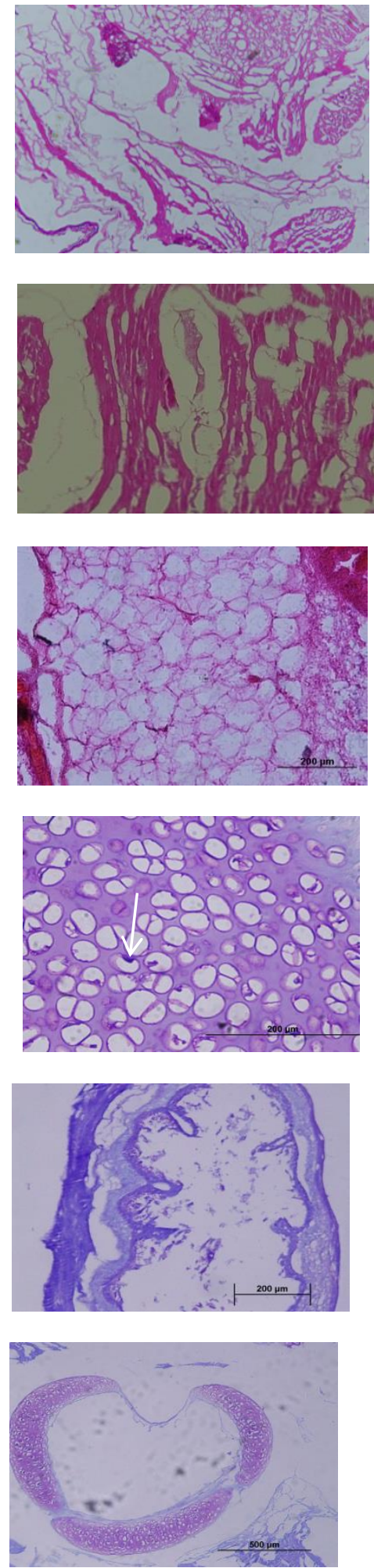
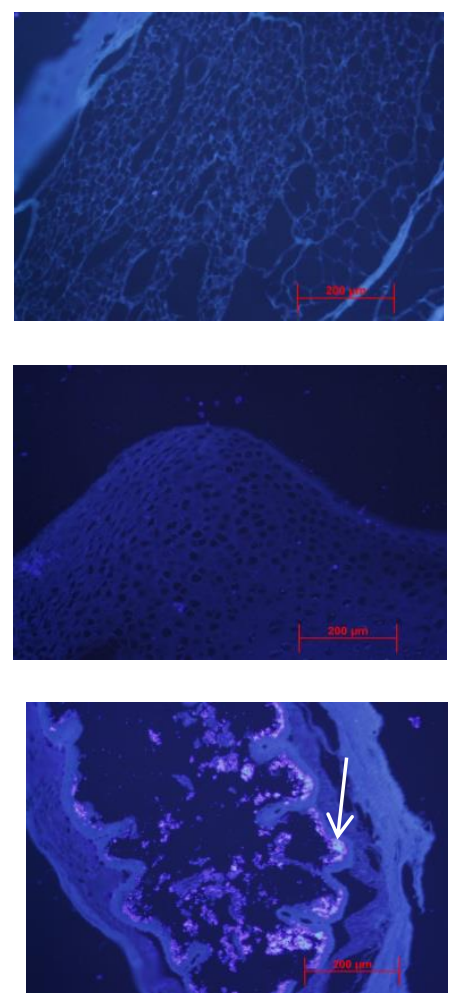

DAPI
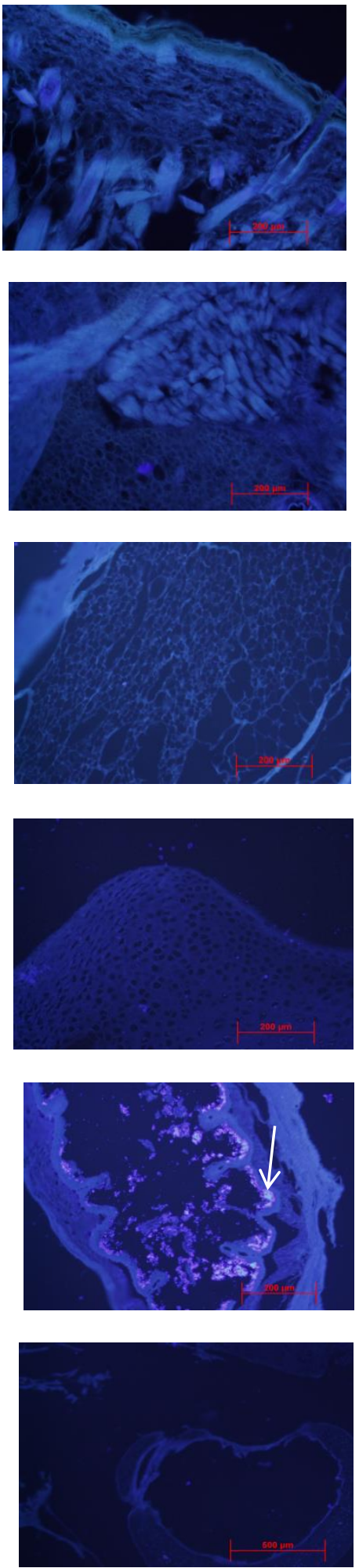

Figure 3: Histological images of some normal and decellularized mouse neck tissues. Some decellularized tissues, such as cartilage and esophagus, contained small amounts of DNA that were trapped within the scaffolds. Arrows indicate the position of DNA molecule 

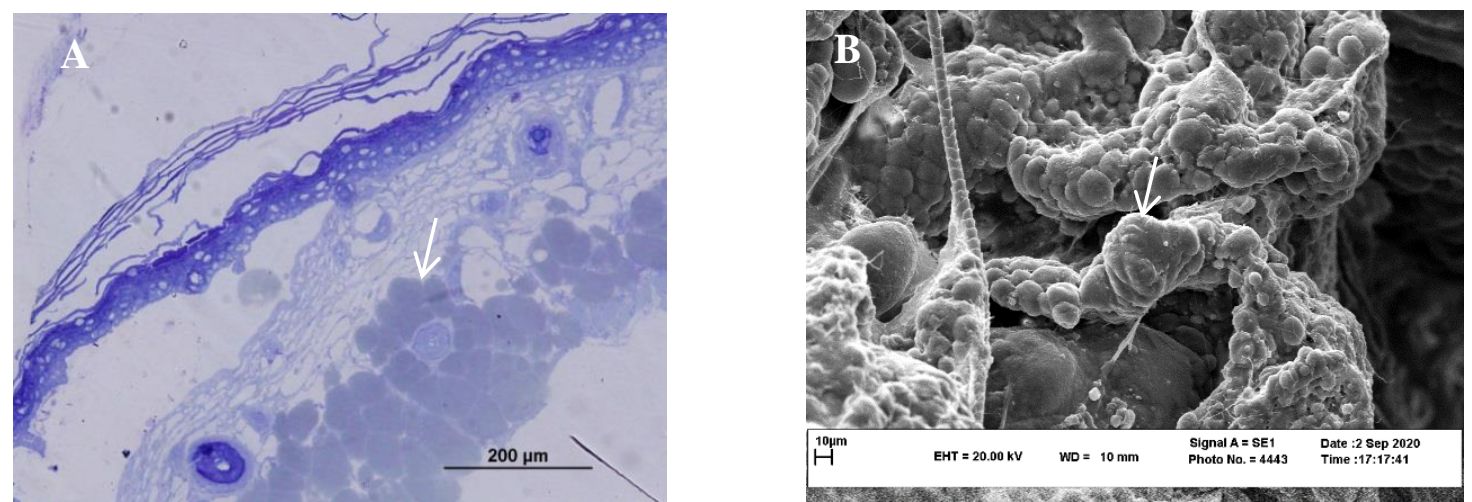

Figure 4: Display of residual fat vacuoles in the mouse neck skin scaffold. Arrows indicate fat vacuoles. A: semi-thin preparation (toluidine blue staining). B: scanning electron microscopy

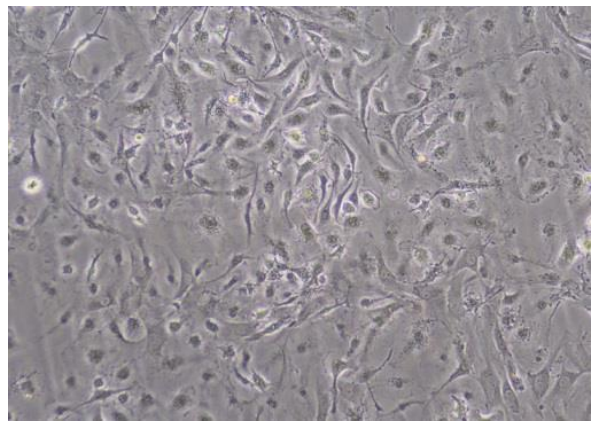

Figure 5: Display of mouse BM-MSCs in the fourth passage
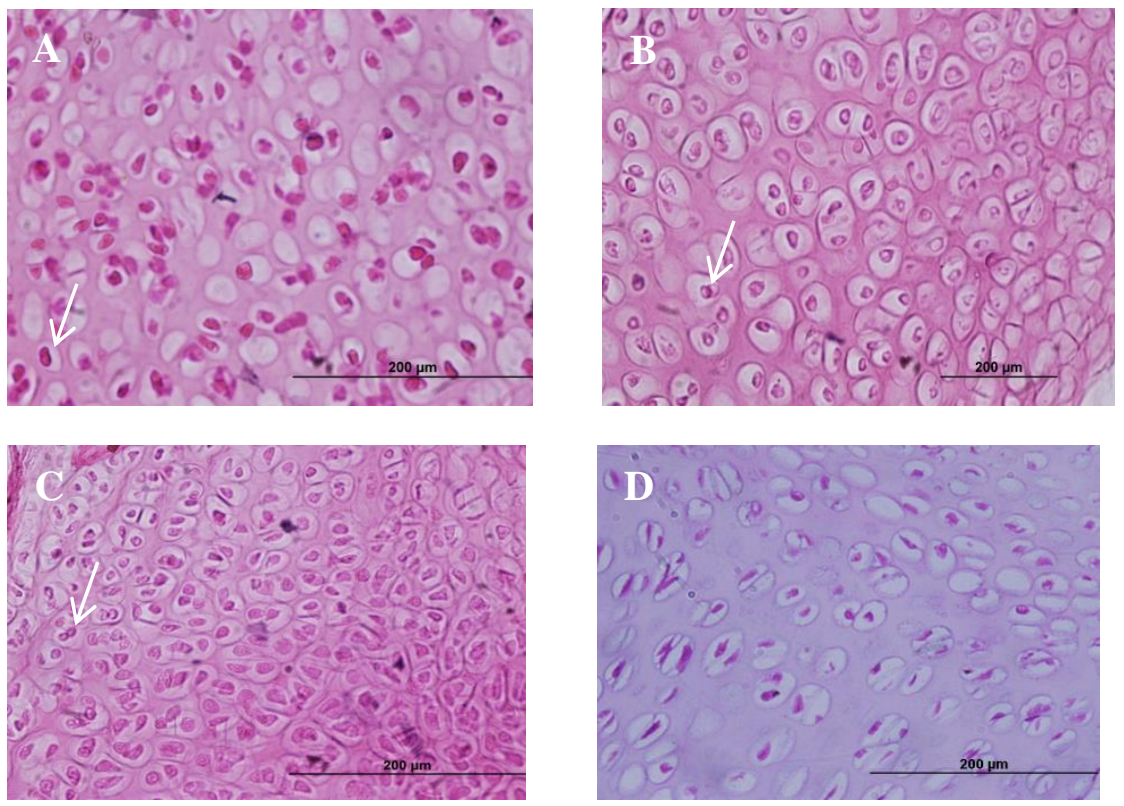

Figure 6: Migration of BM-MSCs to mouse neck cartilage scaffold on third (A), seventh (B), fourteenth (C) and twenty first (D) days of culture. Arrows indicate cell division. H\&E staining 

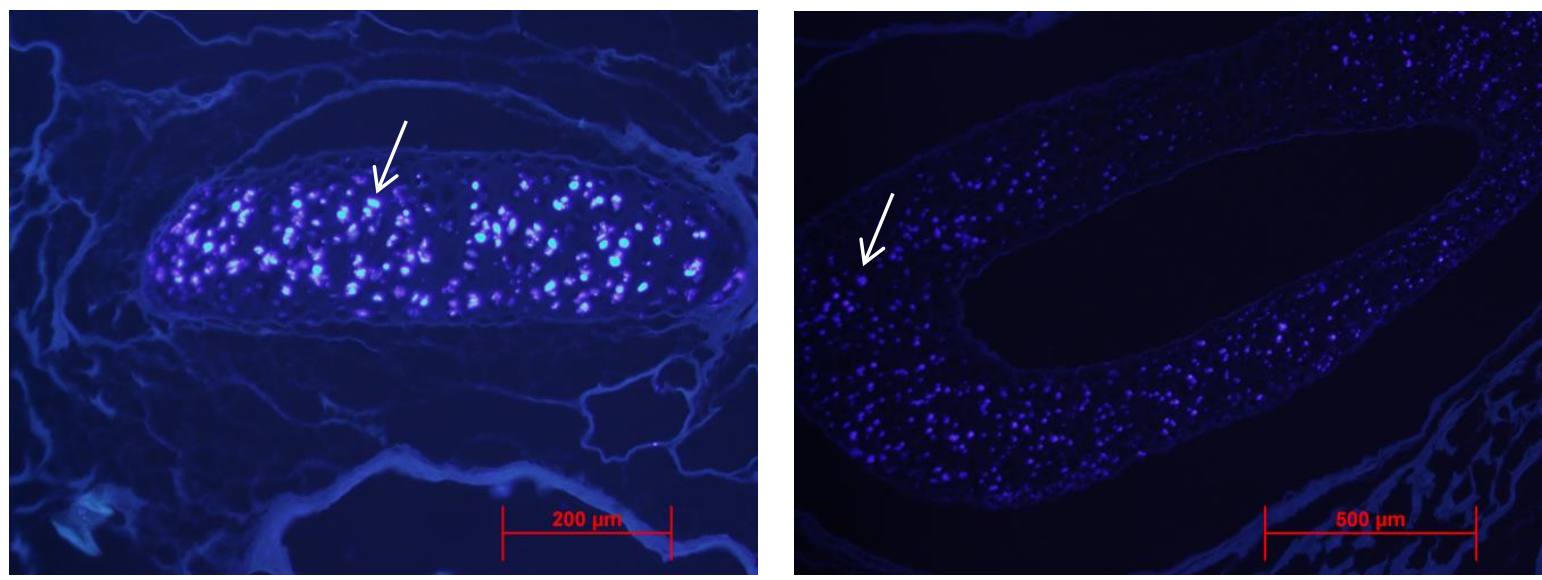

Figure 7: Migration of BM-MSCs to mouse neck cartilage scaffold on fourteenth day of culture. Arrows indicate BM-MSCs. DAPI staining

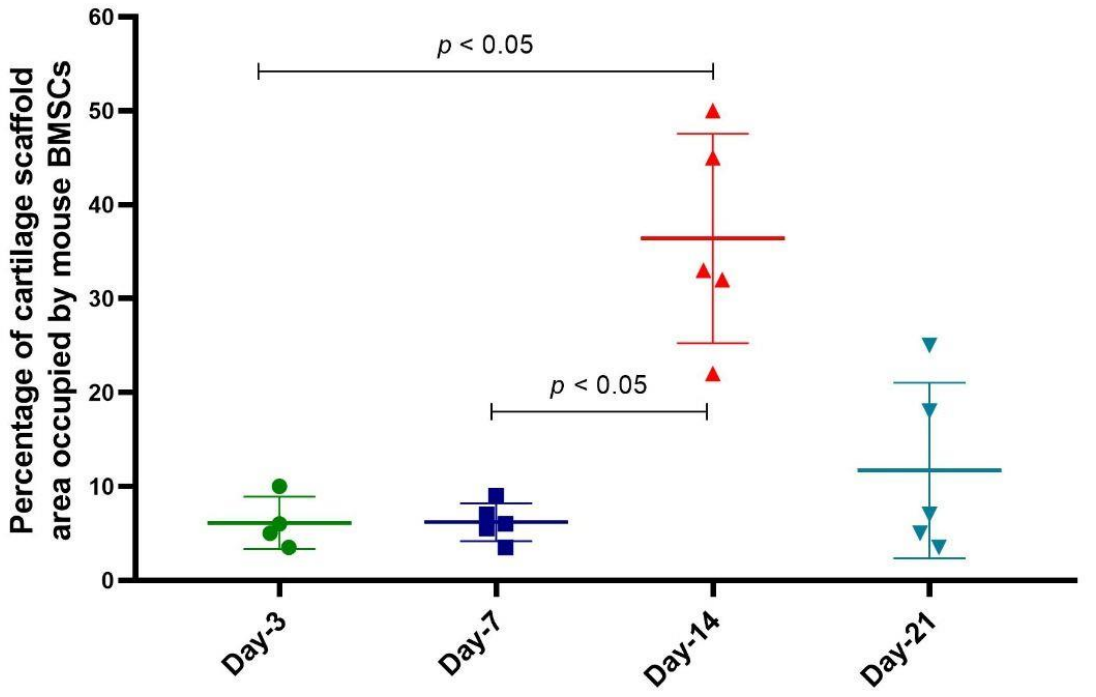

Diagram 1: Percentage of cartilage scaffold area occupied by BMSCc on third, seventh, fourteenth and twenty first days of culture. The statistically significant $p$ values between different days were obtained for Day-14 vs. Day-3 and Day-7 ( $p<0.05)$ 


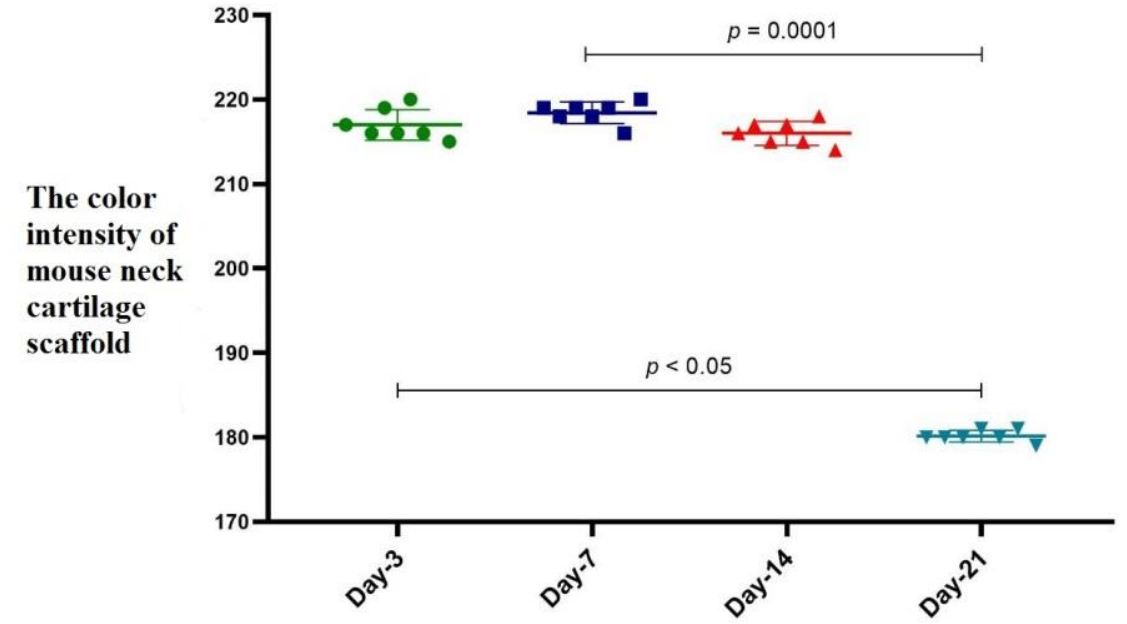

Diagram 2: The color intensity of mouse neck cartilage scaffold on third, seventh, fourteenth and twenty first days of culture. The statistically significant $p$ values between different days were obtained for Day-21 vs. Day-3 $(p<0.05)$ and Day-7 ( $p=0.0001)$
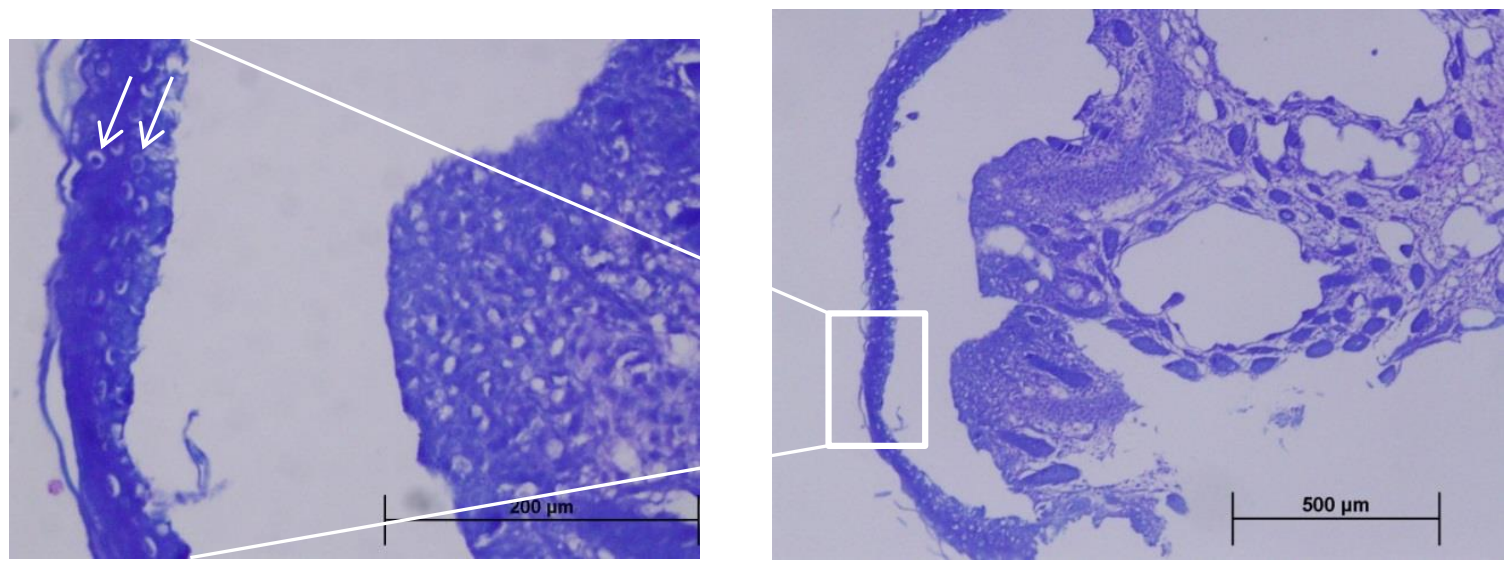

Figure 8: Migration of BM-MSCs to mouse neck epidermal scaffold on fourteenth day of culture. Arrows indicate BM-MSCs. Toluidine blue staining 

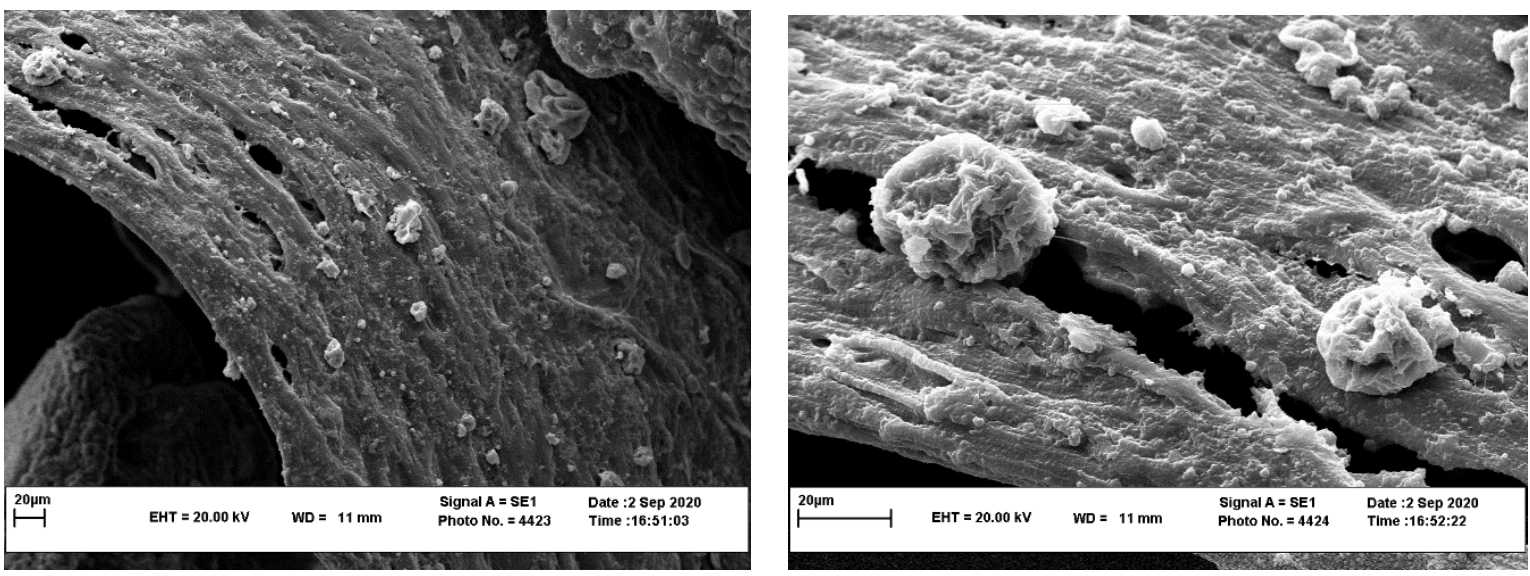

Figure 9: Migration of BM-MSCs to mouse neck vascular blood scaffold on fourteenth day of culture. Scanning electron microscopy

\section{DISCUSSION}

In recent decades, many investigations have been done on the development of scaffolds derived from natural materials in order to improve clinical applications in tissue engineering. Decellularization is a tissue treatment process which eliminates cells. This process is often used to create bio-artificial organs [15]. So far, various decellularization methods have been proposed to develop extracellular matrix-derived scaffolds [16, 17]. For therapeutic applications, it is important to remove antigenic epitopes from the intra and extracellular matrix to prevent immune responses [18]. Studies have demonstrated that removal of DNA is more difficult than other intracellular compounds, because it tends to adhere to extracellular matrix proteins [19]. DNA remaining after decellularization might be a reason for inflammatory reactions following implantations [20]. In addition to DNA, the presence of other cellular compounds such as lipids and cellular proteoglycans can also trigger immune responses [21]. Some investigations have even shown that extracellular matrix of decellularized tissues can elicit an immune response [22], and in order to eliminate inflammatory responses completely it is better to remove fibronectin from the extracellular matrix [23]. However, Gilbert et al [24] showed that some commercially used extracellular scaffolds, despite significant amounts of DNA and positive staining for some nuclear materials, have not produced specific inflammatory responses during clinical applications.

Investigations have reported that snap freeze-thaw cycles followed by treatment with detergents would lead to removal of cellular components from tissues [25, 26]. Although freeze-thaw cycles destroy cells and cellular proteins, some cellular compounds such as nucleus are not removed by this process, and treatment with various detergents is required to remove cellular compounds completely [26]. Elder et al [27, 28] found that using a detergent in conjunction with the freeze-thaw cycles resulted in better decellularization. Their study on bovine articular cartilage showed that among the various decellularizing materials including; SDS, Triton X100, hypertonic and hypotonic solutions, SDS is the best one.
On the other hand, their findings showed that nucleases have little effect on removing DNA molecule of this tissue. Investigations have even shown that SDS retains extracellular matrix molecules and does not reduce the stiffness of decellularized tissues [29]. So far, various tissues such as human and bovine articular cartilage, adult pig kidney, bovine pericardial tissue, ovine esophageal tissue and etc have been well decellularized by SDS treatment [28, 30, 31, 32].

Our study showed that using $2.5 \%$ SDS for 3 hours didn't have a suitable effect on decellularization of mouse neck tissues while using $5 \%$ SDS for the same time, removed all mouse neck tissue cells. However, despite the complete removal of cells and cellular compounds from many tissues, fragments of the DNA molecule were trapped within the lacunae of cartilage as well as the elastic tissue of the esophagus. More detailed studies using scanning electron microscopy and semi-thin investigations showed that despite the complete removal of DNA from skin tissue, some fat vacuoles remained within this scaffold. Using higher doses of SDS to remove DNA from cartilage and esophageal scaffolds and fat vacuoles from dermal scaffold completely could lead to further degradation of extracellular matrix compounds, and it was not necessary.

Investigations have shown that physical properties such as rigidity, porosity and topography are able to influence various biological functions, like cell division, tissue polarity and cell migration [33]. Tavassoli et al [30] studied the interaction of rat bone marrow-derived stem cells and acellularized bovine articular cartilage. Although, in their study, mesenchymal stem cells migrated to cartilage scaffold on third, seventh and fourteenth days of culture, unlike our study, no cell division was reported in these days. Comparison of mouse neck cartilage with bovine articular cartilage scaffold [30] showed that mouse neck cartilage scaffold has more porosity and regularity than bovine scaffold. Porosity and pore size of the scaffold provide growth factors and nutrients and regulate cell growth as well as infiltration for damaged tissue during clinical applications [5, 34]. For this reason, scaffolds that are used in tissue engineering for repairing tissues such as 
bone and cartilage should have appropriate pore size and internal pore connections [35]. Bobbert et al [36] showed that among various materials used in tissue engineering, scaffolds with small pores (200-300 micrometers) provide a better environment for cell growth, but scaffolds with rectangular and large spherical pores are not suitable in bone tissue engineering. Other investigations emphasize that scaffolds with regular pores have more effect on cell growth and exchange of food and excrement, as well as on preservation of extracellular matrices, than scaffolds with random pores [37, 38].

In recent decades, the importance of substrate stiffness as a mechanism for determining cellular behavior has also extensively been studied. For example cellular behaviors such as cell proliferation, differentiation and even apoptosis is influenced by substrate stiffness [39]. The stiffness of human body tissues usually runs from very stiff, such as Achilles' tendon (ca. $310 \mathrm{MPa}$ ), to very soft, such as mammary glands (ca. $160 \mathrm{~Pa}$ ) [40]. Investigations emphasize that cell division occurs more frequently in more rigid than in softer environments in vitro [41, 42]. However MSCs long-term culturing on rigid substrata leads to decreased growth rates and eventual senescence, with concomitant decreases in the differentiation propensity and telomere length [43, 44]. Importantly, there is mounting evidence that mechanical factors may play critical roles in controlling stem cell fate and lineage determination [45].

On the other hand, it seems that because of their strong inductive effects, highly negatively charged proteoglycanrich compounds like hyaluronic acid in cartilage, skin and vascular blood scaffolds as well as elastin molecule in skin and blood vessel scaffolds (table 1) may be among other factors contributing to the occurrence of cellular behaviors shown in our study $[46,47,48]$.

Table 1: Some of the most popular extracellular matrix compounds in cartilage, skin and blood vascular tissues $[49,50]$

\begin{tabular}{|l|l|}
\hline Tissue & Extracellular matrix compounds \\
\hline Cartilage & $\begin{array}{l}\text { Type II Collagen, aggrecan } \\
\text { (containing keratin sulfate \& } \\
\text { chondroitin sulfate), hyaluronic acid, } \\
\text { chondronectin }\end{array}$ \\
\hline Skin & $\begin{array}{l}\text { Hyaluronic acid, dermatan sulfate, } \\
\text { elastin, type II \& III collagen }\end{array}$ \\
\hline Blood vascular & $\begin{array}{l}\text { Elastin, type 1 \& III collagen, } \\
\text { hyaluronic acid }\end{array}$ \\
\hline
\end{tabular}

Like Tavassoli al's [51] study, the color intensity of our scaffold was reduced on 21st day of culture (figure 6D \& Diagram 2), probably due to the extensive migration of stem cells and destructive effect of their degrading enzymes.

\section{CONCLUSION}

As indicated by the results of the present study, among the various extracellular matrices in the mouse neck scaffold; cartilage, epidermal and vascular blood scaffolds have the greatest impact on mouse BM-MSCs behavior. Proper porosity and the presences of highly negatively charged proteoglycans (in cartilage, epidermal and vascular blood scaffolds) as well as the suitable stiffness (in cartilage scaffold) may probably be among the factors that caused mouse BM-MSCs to migrate and divide in our study.

\section{REFERENCES}

1- Solorio, W. CH. D., Alsberg, E. (2016). Decellularized tissue and cell-derived extracellular matrices as scaffolds for orthopedic tissue engineering. Biotechnology Advances 2346.

2- $\quad$ Greggio, C., De Francesch, F., Figueiredo, L.M., Gobaa, S., Ranga, A., Semb, H., et al. (2013).Artificial threedimensional niches deconstruct pancreas development in vitro. Development 140: 4452-62.

3- Samare-Moosavi, S., Saadatfar, Z., Mahdavi-shahri, N., Behnam-Rasoli, M., Lari, R. (2019). Cell matrix interaction in decellularized pancreatic natural 3D scaffold with heparin sulfate. elJPPR 9(6): 21-28.

4- Saxena, A. K. (2010). Tissue engineering and regenerative medicine research perspectives for pediatric surgery. Pediatr Surg Int 26(6): 557-73.

5- Abdulghani, S., Mitchell, G. R. (2019). Biomaterials for In Situ Tissue Regeneration: A Review. Biomolecules 9 (750): 1-24.

6- Friedl, P., Wolf, K. (2003). Tumor-cell invasion and migration: diversity and escape mechanisms. Nature Reviews Cancer 3(5):362-74.

7- Caplan, A.I. (2000). Tissue engineering designs for the future: new logics, old molecules. Tissue Eng 6(1):1-8.

8- Corcoran, J. P., Ferretti, P. (1999). RA regulation of keratin expression and myogenesis suggests different ways of regenerating muscle in adult amphibian limbs. J Cell Sci 112 (Pt 9): 1385-94.

9- Rozario, T., DeSimone D.W. (2010). The Extracellular Matrix In Development and Morphogenesis: A Dynamic View. Dev Biol 341(1): 126-140.

10- Bonab, M.M., Alimoghaddam, K., Talebian, F., et al. (2006). Aging of mesenchymal stem cell in vitro. BMC Cell Biol 7: 14-21.

11- Cao, Y., Croll, T.I., Lees, J.G., Tuch, B.E., Cooper-white, J. J. (2005). Scaffolds, Stem cells, and Tissue Engineering: a potent Combination. Australian Journal of Chemistry 58(10): 691-703.

12- Lu, Q., Ganesan, K., Simionescu, D.T., Vyavahare, N. R. (2004). Novel porous aortic elastin and collagen scaffolds for tissue engineering. Biomaterials 22:5227-5237.

13- Hoshiba, T., Chen, G., Endo, C., Mrauyama, H., Wakui, M. Nemoto, E., Kawazoe, N., Tanaka, M. (2016). Decellularized extracellular matrix as an In Vitro model to study the comprehensive roles of the ECM in stem cell differentiation. Hindawi publishing corporation 10(1155): 1-10.

14- Bozzola, L., Russell, D. (1999). Electron microscopy, Principles and Techniques for Biologists. Jones and Bartlett, Boston 670 p.

15- Ghasroldasht, M. M., Irfan-Maqsood, M., Matin, M. M., Bidkhori, H. R, Naderi Meshkin, H., Moradi, A., et al. (2014). Mesenchymal stem cell based therapy for osteodiseases. Cell Biol Int 38:1081-1085.

16- Neshati, Z., Matin, M. M., Bahrami, A. R., Moghimi, A. (2010). Differentiation of mesenchymal stem cells to insulinproducing cells and their impact on type 1 diabetic rats. J Physiol Biochem 66:181-187.

17- Jia, S., Liu, L., Pan, W., Meng, G., Duan, C., Zhang, L., et al. (2012). Oriented cartilage extracellular matrix-derived scaffold for cartilage tissue engineering. J Biosci Bioeng 113:647-653.

18- Benders, K. E., Weeren, P. R., Badylak, S. F., Saris, D. B., Dhert, W. J., Malda, J. (2013). Extracellular matrix scaffolds for cartilage and bone regeneration. T Trends Biotechnol.

19- Ross, J. R., Kirk, A. D., Ibrahim, S. E., Howell, D. N., Baldwin, W.M., Sanfilippo, F. P. (1993). Characterization of 
human anti-porcine "natural antibodies" recovered from ex vivo perfused hearts--predominance of $\lg \mathrm{M}$ and $\lg \mathrm{G} 2$. Transplantation 55:1144-1150.

20- Gilbert, T.W., Stolz, D.B., Biancaniello, F. (2006). Decellularization of tissue and organs. Biomaterials 27(19): 3675-3683.

21- Nagata, S., Hanayama, R., Kawane, K. (2010). Autoimmunity and the clearance of dead cells. Cell 140:619 630.

22- Dahm, M., Lyman, W.D., Schwell, A. B., Factor, S. M., et al (1999). Immunogenicity of glutaraldehyde-tanned bovine pericardium. Journal of Cardiovascular Surgery 99: 10821090.

23- Coito, A. J., Kupiec-Weglinski, J. W. (1996). Extracellular matrix proteins: by standers or active participant in the allograft rejection cascade? Ann Transplant 1:14-18.

24- Gilbert, T. W. F., Badylac, S. F. (2009). Quantification of DNA in biologic scaffold materials. Surg Res 152: 135-139.

25- Stapleton, T.W., Ingram, J., Katta, J., Knight, R., Korossis, S., Fisher. J., et al. (2008). Development and characterization of an acellular porcine medial meniscus for use in tissue engineering. Tissue Eng Part A14:505-518.

26- Murphy, C.M., Matsiko, A., Haugh, M. G., Gleeson, J. P., Obrien, F. J. (2012). Mesenchymal stem cell fate is regulated by the composition and mechanical properties of collagen glycosaminoglycan scaffolds. J Mech Behav Biomed Mater 11:53-62.

27- Elder, B. D., Eleswarapu, S. V., Athanasiou, K. A. (2009). Extraction techniques for the decellularization of tissue engineered articular cartilage constructs. Biomaterials 30(22):3749-3756.

28- Elder, B. D., Kim, D, H., Athanasiou, K. A. (2010). Developing an articular cartilage decellularization of tissue engineered articular cartilage constructs. Biomaterials 30(22): 3749-3756.

29- Rosario, D. J., Reilly, G. C., Ali Salah, E., Glover, M., Bullock, A. J., Macneil, S. (2008). Decellularization and sterilization of porcine urinary bladder matrix for tissue engineering in the lower urinary tract. Regen. Med 3(2): 145-156.

30- Tavassoli, A., Moghaddam-Matin, M., Akbarzade-Niaki, M. Mahdavi- Shahri, N., Shahabipour, F. (2015). Mesenchymal stem cells can survive on the extracellular matrix derived decellularized bovine articular cartilage scaffold. Iranian Journal of Basic Medical Sciences 18(12): 1-8.

31- Ackbar, R. Ainoedhofer, H. Gugatschka, M. Saxena, A. K. (2012). Decellularized ovine esophageal mucosa for esophageal tissue engineering. Technol Health Care 20(3):215-223.

32- Shahabipour, F., Mahdavi-shahri, N., Moghadam-matin, M., Tavasoli, A., Zebarjad, S. M. (2013). Scaffolds derived from cancellous bovine bone support mesenchymal stem cells' maintenance and growth. In Vitro Cell.Dev.Biol.-Animal 49:440-448.

33- Lu, P., Weaver, V. M., Werb, Z. (2012). The extracellular matrix: a dynamic niche in cancer progression, J. Cell Biol 196: 395-406

34- Chen, Y., Zhou, S., Li, Q. (2011). Microstructure design of biodegradable scaffold and its effect on tissue regeneration. Biomaterials 32: 5003-5014.

35- Mandal, B. B., Kundu, S. C. (2009). Cell proliferation and migration in silk fibroin 3D scaffolds. Biomaterials 30(15): 2956-2965

36- Bobbert, F.S.L., Zadpoor, A.A. (2017). Effects of bone substitute architecture and surface properties on cell response, angiogenesis, and structure of new bone. $\mathrm{J}$. Mater. Chem. B 5: 6175-6192.

37- Arora, A., Kothari, A., Katti, D.S. (2015). Pore orientation mediated control of mechanical behavior of scaffolds and its application in cartilage-mimetic scaffold design. J. Mech. Behav. Biomed. Mater 51: 169-183.

38- Dai, Y., Shen, T.; Ma, L., Wang, D., Gao, C. (2018). Regeneration of osteochondral defects in vivo by a cell-free cylindrical poly (lactide-co-glycolide) scaffold with a radially oriented microstructure. J. Tissue Eng. Regen. Med 12: 1647-1661

39- Hoffman, B. D., Grashoff, C., Schwartz, M. A. (2011). Dynamic molecular processes mediate cellular mechanotransduction. Nature 475: 316-23.

40- Levental, I., Georges, P. C., Janmey, P. A. (2007). Soft biological materials and their impact on cell function. Soft Matter 3: 299-306.

41- Georges, P. C., Janmey, P. A. (2005). Cell type- specific response to growth on soft materials. Biomechanics and Mechanotransduction in Cells and Tissues 98: 1547-1553.

42- Mi, H.Y., Jing, X., Salick, M.R., Cordie, T.M., Peng, X.F., Turng, L.S. (2014). Morphology, mechanical properties, and mineralization of rigid thermoplastic polyurethane/hydroxyapatite scaffolds for bone tissue applications: effects of fabrication approaches and hydroxyapatite size. J. Mater. Sci 49: 2324-2337.

43- Banfi, A., Muraglia, A., Dozin, B., et al. (2000). Proliferation kinetics and differentiation potential of ex vivo expanded human bone marrow stromal cells: implications for their use in cell therapy. Exp Hematol 28: 707- 15.

44- Bonab, M. M., Alimoghaddam, K., Talebian, F., et al. (2006) Aging of mesenchymal stem cell in vitro. BMC Cell Biol 7: 14-21.

45- Guilak, F, Cohen, D. M., Estes, B. t., Gimblr, J. M., Liedtke, W., Chen, C. S. (2009). Control of Stem Cell Fate by Physical Interactions with the Extracellular Matrix. Cell Stem Cell 6(16): 1-10.

46- Ghanbari, H., Saghravanian, N., Zakery, M., Mahdav Shahri, N., et al. (2008). Histological evaluation of Curcuma longa-ghee formulation and hyaluronic acid on gingival healing in dog. Journal of Ethnopharmacology 120: 335341.

47- Shahi, M., Mohammadnejad D., Karimipour, M., Rasta, S. H., Rahbarghazi, R., Abedelahi, A. (2020). Hyaluronic acid and regenerative medicine: new insight in to stroke therapy. Curr Mol Med 20(9): 675-691.

48- Fujimoto, N., Tajima, S., Ishibashi, A. (2000). Elastin peptides induce migration and terminal differentiation of cultured keratinocytes via $67 \mathrm{kDa}$ elastin receptor in vitro: 67 $\mathrm{kDa}$ elastin receptor is expressed in the keratinocytes eliminating elastic materials in elastosis perforans serpiginosa. J Invest Dermatol 115(4): 633-639.

49- Mescher, A. (2018). Junqueiras Basic Histology: Text and Atlas. 15h Edition. McGraw-Hill.

50- Longas, M. O., et al. (1987). Evidence for structural changes in dermatan sulfate and hyaluronic acid with aging. Carbohydr. Res 159: 127-136.

51- Tavassoli, A., Shahabipour, F., Mahdavi Shahri, N., Moghadam Matin, M., Fereidoni, M. (2010). In vitro experimental study of interactions between blastema tissue and three-dimensional matrix derived from bovine cancellous bone and articular cartilage. Journal of Cell and Tissue 1(1):53-62. [Article in Persian]. 